\title{
Lithium Ion Storage Characteristics of Mechanically Fractured Titanate Nanotubes
}

\author{
Jeongeun Kim, ${ }^{1}$ Minyong Eom, ${ }^{2}$ Yongsub Yoon, ${ }^{1}$ and Dongwook Shin ${ }^{1,2}$ \\ ${ }^{1}$ Department of Materials Science and Engineering, Hanyang University, 222 Wangsimni-ro, Seongdong-gu, \\ Seoul 133-791, Republic of Korea \\ ${ }^{2}$ Department of Fuel Cells and Hydrogen Technology, Hanyang University, 222 Wangsimni-ro, Seongdong-gu, \\ Seoul 133-791, Republic of Korea
}

Correspondence should be addressed to Dongwook Shin, dwshin@hanyang.ac.kr

Received 8 February 2012; Revised 30 July 2012; Accepted 30 July 2012

Academic Editor: Mauro Coelho dos Santos

Copyright () 2012 Jeongeun Kim et al. This is an open access article distributed under the Creative Commons Attribution License, which permits unrestricted use, distribution, and reproduction in any medium, provided the original work is properly cited.

The effect of mechanical milling on the formation of short titanate nanotube and structural change induced is investigated. Mechanical milling produces the short nanotubes with the length of $30-160 \mathrm{~nm}$. The lithium ion intercalation characteristics of the obtained short titanate nanotube were studied to verify the effect of the newly formed cross-sections of nanotubes. It was found that the protonated titanate nanotubes maintained long shapes until $30 \mathrm{~min}$ of mechanical milling and were transformed into agglomerated nanosheets and finally anatase granules depending on the treatment duration. Through galvanostatic investigation, the nanotubes with milling of 15 min exhibited the highest discharge capacity of $336 \mathrm{mAh} \cdot \mathrm{g}^{-1}$ in first cycle, $12.4 \%$ larger than pristine.

\section{Introduction}

Nanostructured electrodes fabricated from nanotubes, nanowires, or nanofibers have shown unique rate capability for lithium ion batteries since the distance $\mathrm{Li}^{+}$ions penetrate is as small as several nanometers in the radius direction which is significantly smaller than that in the usual power. As a result, there is tremendous research interest in the development of nanostructured Li-ion battery electrode with high capacity and excellent cycling stability [1-6].

Many researchers have recently prepared titanate nanotubes and developed their electrochemical properties by precise control over their morphology for various applications. It has been found that the properties of these nanomaterials depend strongly on their size and shape. Therefore, it is important to control their size and the morphology to make use of them in suitable applications. Especially much attention has been paid to nanotubes for electrochemical lithium storage due to their open, mesoporous structure, large specific surface, efficient transport of lithium ions, and impressive ion-exchange properties, which result in a high value of charge/discharge capacity [7-12].

Li et al. and Zhou et al. reported on the effect of the titanate morphology produced by changing process parameters on the battery performance [13-16]. Bavykin et al. reported the rate of ion exchange along length of titanate nanotubes [17]. For the shortest nanotubes (having an average length ca. $50 \mathrm{~nm}$ ), the characteristic time of the ion exchange was shorter than that for long nanotubes, suggesting that the diffusion of ions along the length of the tube could be the rate-limiting step. Although this finding was pioneering, they did not investigate the effect of titanate nanotube length on the electrochemical characteristics as an anode material for lithium battery. It is our main objective to carry out the basic estimation on the battery performance of titanate nanotubes with various lengths and verify the possibility of improving the poor cyclability of titanate nanotubes, by changing the nanotube length.

For an anode for lithium ion battery, it was confirmed that, at the first discharge stage, lithium intercalation occurred at inner and outer surface of nanotube. Some of these intercalated lithium ions could not be extracted from deep interlayer sites on inner surface of the nanotube and, hence, electrochemical reactions occur actively only at the both end of nanotubes $[15,16,18]$. In the interests of large surface area for electrochemical reaction sites of $\mathrm{Li}_{x} \mathrm{TiO}_{2}$ and short nanochannel for easy and fast transport 


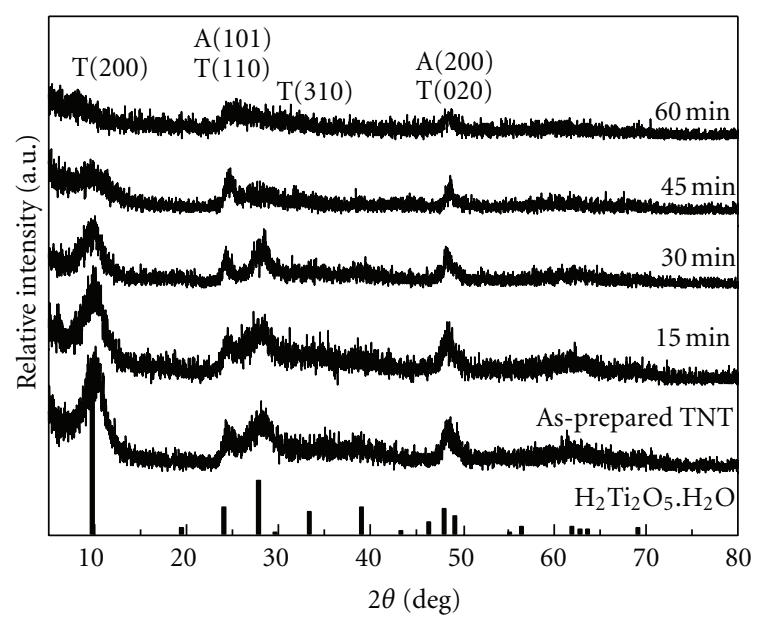

A: anatase

T: TNT

FIGURE 1: XRD patterns of the as-prepared titanate nanotubes and the produce of mechanical milling.

of Li ion for lithium intercalation, we synthesized the short length of nanotubes by low-energy mechanical milling from the hydrated titanate nanotubes synthesized via alkaline hydrothermal treatment of $\mathrm{TiO}_{2}$ and subsequent acid treatment $[19,20]$. To verify the effect of mechanical milling treatment on titanate nanotube for battery performance, the length of the titanate nanotube was controlled by various milling condition, and basic charging-discharging behavior of nanotubes as anode was estimated.

\section{Experimental Methods}

Titanate nanotubes were prepared by alkali hydrothermal method. Commercial titanium oxide powder (P25, Degussa AG) was used as a precursor to synthesize titanate nanotubes (TNTs). $4 \mathrm{~g}$ of the $\mathrm{TiO}_{2}$ precursor and $180 \mathrm{~mL}$ of $10 \mathrm{M} \mathrm{NaOH}$ (98\%, SAMCHUN) aqueous solution were mixed under stirring for $3 \mathrm{~h}$. The suspension was poured into a Teflon vessel and placed in autoclave for hydrothermal treatment at $130^{\circ} \mathrm{C}$ for $24 \mathrm{~h}$ and cooled to room temperature. The synthesized solution was washed for $24 \mathrm{~h}$ with $\mathrm{HCl}$ (35\%, DAEJUNG) acid solutions in $\mathrm{pH} 1$ and then washed continuously with distilled waters to $\mathrm{pH} 7$ to remove to extract sodium. The samples were filtered and dried at $60^{\circ} \mathrm{C}$ for $24 \mathrm{~h}$. Titanate nanotubes were treated in a mechanical ball milling using identical milling parameters. The milling performed in air using a Fritsch planetary ball mill, with balls made of zirconium dioxide. The powder-to-ball weight ratio was chosen to be 1 (powder): 15 (ball), while the milling time was varied from 15 to $60 \mathrm{~min}$ under the rotational speed of $100 \mathrm{rpm}$.

The morphology and structural changes of titanate nanotubes with various milling conditions were characterized using BET (Surface Characterizing Analyzer, ASAP2010 \& TriStar3000, USA), (X-ray diffraction XRD, Rigaku dmax 3000, Japan), (High Resolution Transmission Electron Microscopy TEM, JEM-2100F, Japan), and (Field Emission Scanning Electron Microscopy FE-SEM, Hitachi S-4800, Japan).
(Thermogravimetric-differential thermal analysis TGDTA, TGA7, PERKIN ELMER) was performed with a temperature range of room temperature to $500^{\circ} \mathrm{C}$.

For fabrication of electrodes, the active materials prepared with the mixture of carbon black, and isopropyl alcohol, and the obtained titanate nanotubes were coated on copper foil and, then, dried at $120^{\circ} \mathrm{C}$ for 12 hours to remove the solvents. The tests were performed on a cointype cell assembled with as-prepared electrode, lithium metal as the counter, separator, and an electrolyte. The electrolyte solution was $\mathrm{LiPF}_{6}$ dissolved in a mixture of EC (ethylene carbonate) and (dimethyl carbonate DMC) with the volume ration of $1: 1$.

Electrochemical properties measuring were using TOSCAT cell test instrument (Toyo system, Japan). Charge and discharge were conducted between 3 and $1 \mathrm{~V}$ versus $\mathrm{Li}^{+}$reference electrode at $0.1 \mathrm{C}$ rate. Cyclic voltammogram was measured from 3 and $1 \mathrm{~V}$ range at $0.2 \mathrm{mV} \cdot \mathrm{s}^{-1}$, using electrochemical interface (SI 1287, UK).

\section{Results and Discussion}

Figure 1 shows the XRD patterns of the as-prepared titanate nanotubes and the mechanically milled in condition of $100 \mathrm{rpm}$ for 15, 30, 45, and $60 \mathrm{~min}$. All the powders exhibited characteristic peaks at around $2 \theta=10^{\circ}, 24^{\circ}$, and $28^{\circ}$, which are assigned to the diffraction of $\mathrm{H}_{2} \mathrm{Ti}_{2} \mathrm{O}_{5} \cdot \mathrm{H}_{2} \mathrm{O}$ (JCPDS, Card 47-0124) with peak broadening by nanometer size [20-23]. It was known that the nanotubes showed weak diffraction lines because of their tubular structure and poor crystallinity [24]. The gradual changes in the major diffraction peaks suggest that the mechanical milling affected both the length and the structure of nanotubes. The intensities of main peaks at $2 \theta=10^{\circ}$ and $28^{\circ}$ of titanate nanotubes were slightly decreased and broadened with increasing milling time, which suggests that nanotube structure was gradually distorted along with shortening by mechanical milling process. Unlike main peaks of nanotube, the peaks at $2 \theta=24^{\circ}$ and $48.5^{\circ}$ were maintained under whole milling conditions. Plodinec et al. confirmed that during the mechanical milling treatment the phase transitions from titanate nanotubes to anatase phase and finally rutile phase were observed since the high-energy ball milling generated defects, and it influenced the composition and the stoichiometry [25]. Similar phase change was observed in this work; nanotube structure was distorted and converted into anatase phase gradually. After milling for $60 \mathrm{~min}$, most of nanotubes seemed to collapse into anatase crystalline granules.

The variation of surface area of the mechanically milled product is summarized in Table 1 . The surface area increases with milling and reached the highest value of $550 \mathrm{~m}^{2} \cdot \mathrm{g}^{-1}$ at $15 \mathrm{~min}$ and then decreases with an increase in the milling time. This is believed to be due to the agglomeration of fractured nanotubes and the anatase granules. At $60 \mathrm{~min}$ of milling the surface area was decreased to $273 \mathrm{~m}^{2} \cdot \mathrm{g}^{-1}$, suggesting that the highly agglomerated anatase granules were formed as supported from XRD data in Figure 1.

Figures 2 and 3 show the HRTEM and FESEM images of the titanate nanotubes. As-prepared titanate nanotubes were 


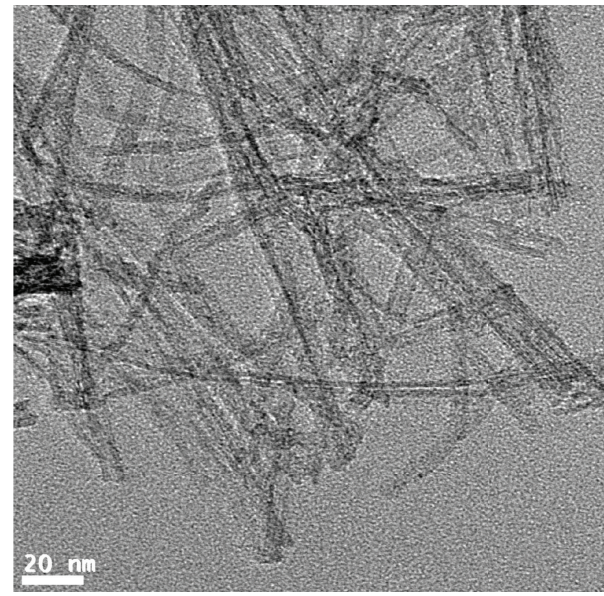

(a)

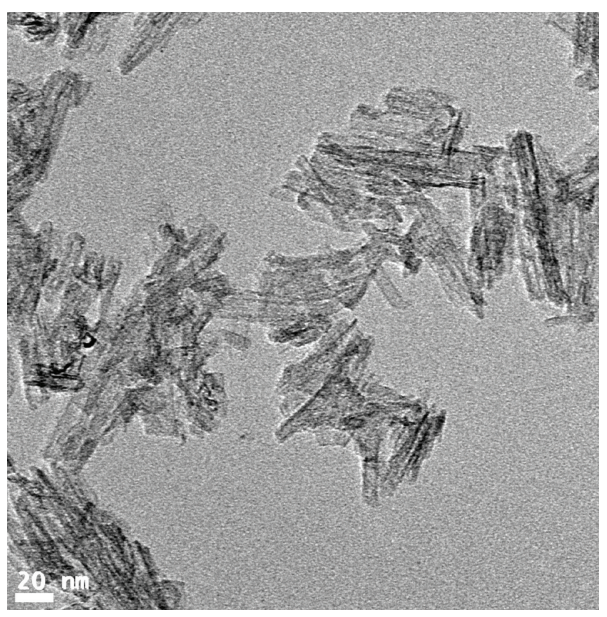

(c)

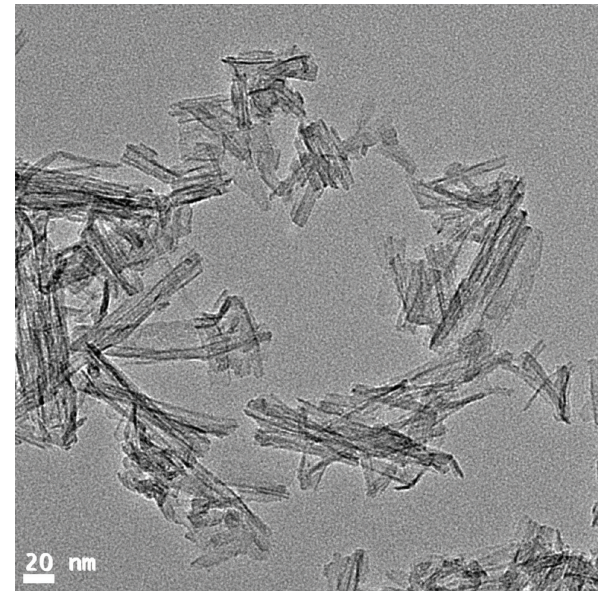

(b)

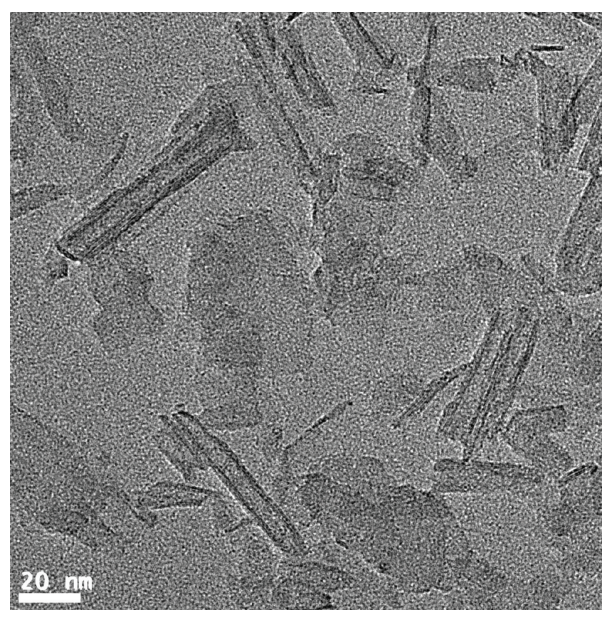

(d)

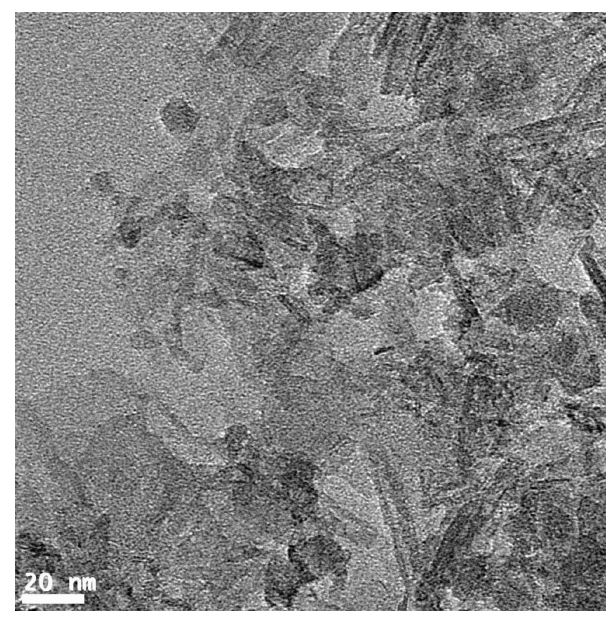

(e)

FIGURE 2: TEM images of (a) the as-prepared protonated titanate nanotubes, and the titanate nanotubes with mechanical milling in condition of (b) 15, (c) 30, (d) 45, and (e) 60 minutes at $100 \mathrm{rpm}$. 


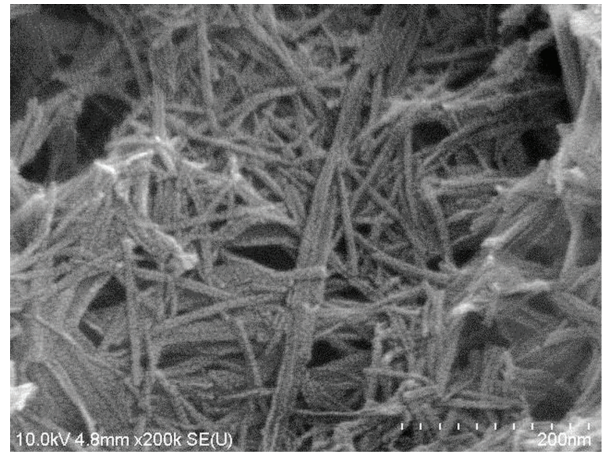

(a)

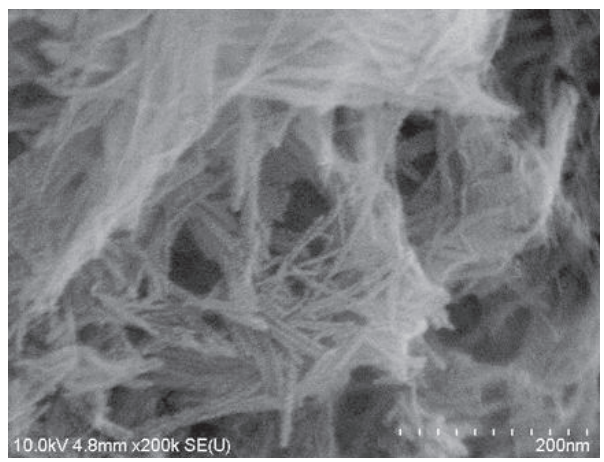

(c)

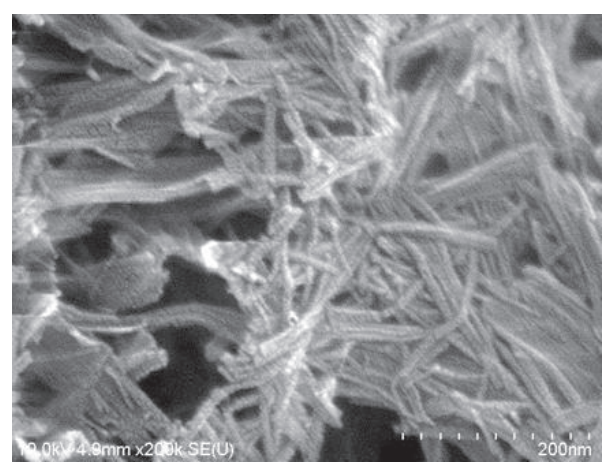

(b)

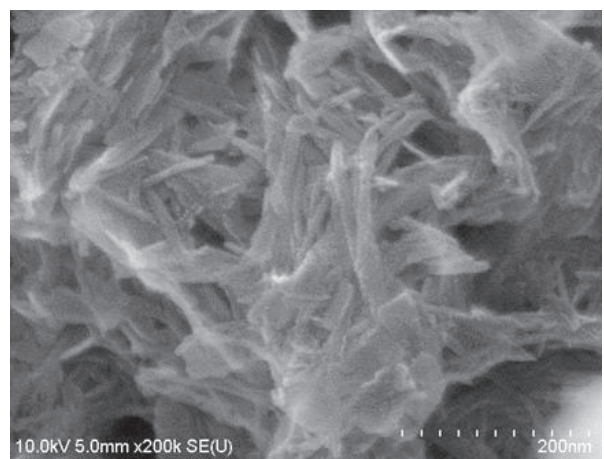

(d)

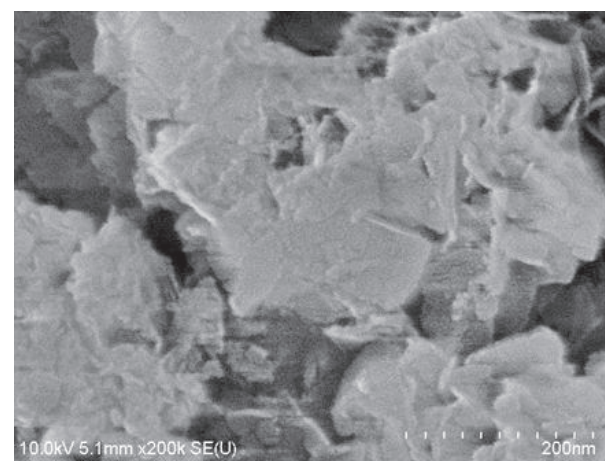

(e)

FIGURE 3: SEM images of (a) the as-prepared protonated titanate nanotubes, and the titanate nanotubes with mechanical milling in condition of (b) 15, (c) 30, (d) 45, and (e) 60 minutes at $100 \mathrm{rpm}$.

TABLE 1: Surface area of the starting material, the as-prepared, and mechanically milled.

\begin{tabular}{lccccc}
\hline Condition of milling $(\mathrm{min})$ & $\mathrm{P} 25$ & 0 & 15 & 30 & 60 \\
Surface area, $\mathrm{S}_{\mathrm{BET}}\left(\mathrm{m}^{2} \cdot \mathrm{g}^{-1}\right)$ & $55-60$ & 500 & 550 & 513 & 273 \\
\hline
\end{tabular}

long and slim tubular shape, whose diameter was around $10 \mathrm{~nm}$ and length was several hundred nanometers. HRTEM image in as-prepared protonated titanate nanotubes shows that the synthesized nanotubes have 4-5 layers with open ends. The nanotubes were slightly shortened by milling for $15 \mathrm{~min}$ to approximately $\sim 100 \mathrm{~nm}$ in length and milling for $30 \mathrm{~min}$ to $30-100 \mathrm{~nm}$. However, the number of wall layers and the size of interspacing remained similar to those of the as-prepared long titanate nanotubes. After $45 \mathrm{~min}$, the particle type granules were observed that the titanate nanotubes were fractured and transformed to anatase particles with excessive milling treatment. XRD data in Figure 1 support that short titanate nanotubes maintained the $\mathrm{H}_{2} \mathrm{Ti}_{2} \mathrm{O}_{5} \cdot \mathrm{H}_{2} \mathrm{O}$ structure up to $30 \mathrm{~min}$ of milling. Figure 3 shows that the partial change of powder morphology took place with milling treatment. It is clear that the degree of agglomeration is slightly intensified with milling time. After $60 \mathrm{~min}$, tubular type morphology is not shown as TEM image, and anatase granules were agglomerated by increased treatment duration.

Figure 4 shows the initial charge/discharge behavior of lithium intercalation in the titanate nanotubes before 


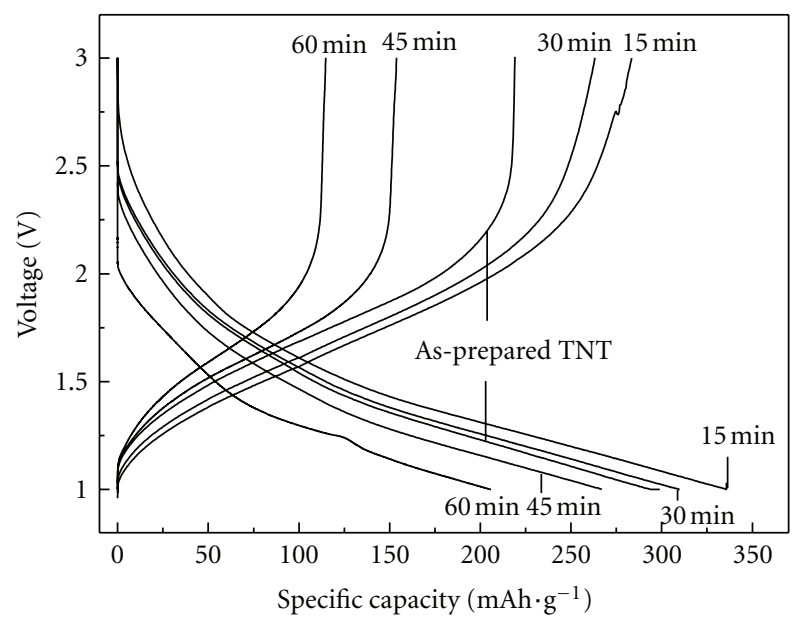

FIGURE 4: Initial charge/discharge profile of titanate nanotubes with the milling condition of $0,15,30,45$ and 60 minutes at a current rate of $10 \mathrm{~mA} \cdot \mathrm{g}^{-1}$ between 1.0 and $3.0 \mathrm{~V}$.

and after milling treatments at current rate of $10 \mathrm{~mA} \cdot \mathrm{g}^{-1}$ between $1.0 \mathrm{~V}$ and $3.0 \mathrm{~V}$. The initial discharge capacities were varied from $335 \mathrm{mAh} \cdot \mathrm{g}^{-1}$ to $210 \mathrm{mAh} \cdot \mathrm{g}^{-1}$, and initial charge capacities were varied from $280 \mathrm{mAh} \cdot \mathrm{g}^{-1}$ to $114 \mathrm{mAh} \cdot \mathrm{g}^{-1}$ depending on milling duration. As-prepared titanate nanotubes exhibited the initial charge and discharge capacity of $219 \mathrm{mAh} \cdot \mathrm{g}^{-1}$ and $299 \mathrm{mAh} \cdot \mathrm{g}^{-1}$, respectively, with a reversible efficiency of $73.2 \%$. However, charge and discharge capacities were increased to $280 \mathrm{mAh} \cdot \mathrm{g}^{-1}$ and $336 \mathrm{mAh} \cdot \mathrm{g}^{-1}$ for milling of $15 \mathrm{~min}$ with a reversible efficiency of $83.3 \%$. After milling of $15 \mathrm{~min}$, the capacities rapidly decreased with increasing milling time. One can see that morphological and structural change, controlling the length of titanate nanotubes, seems to have a noticeable effect on the cell performance. At the initial stage of milling treatment, long nanotubes were fractured into short nanotube that had the highest value of surface area for the absorption of Li ion and short nanochannel for easy and fast transfer of $\mathrm{Li}^{+}$ for lithium intercalation. Further milling treatment, however, starts to produce nanosheets with lower intercalation capability. Due to the increase of less active phases, even though nanotubes are shorten further, the charge/discharge capacities decrease. After $30 \mathrm{~min}$ of milling, the nanotubes transformed to anatase granular structure, and consequently a distinguishing characteristic of nanotubes was disappeared.

Figure 5 shows the cyclic voltammograms of the samples at a scan rate of $0.2 \mathrm{mV} \cdot \mathrm{s}^{-1}$. In the first cycle, there is only a pair of broad redox peaks for nanotubes as prepared and milling 13 and $30 \mathrm{~min}$. The pseudocapacitive behavior of this peak is explained in terms of the interaction taking place on the nanosheet surface, hence curved one. The $\mathrm{TiO}_{2}$ nanotubes hold the curved nanosheet-like morphology with thin-wall structure and high specific surface area.

In the case of the nanotubes with milling $45 \mathrm{~min}$, a pair of shoulder redox peaks near the larger broad redox peaks appears at 1.75 and $1.95 \mathrm{~V}$ (versus $\mathrm{Li}^{+} / \mathrm{Li}$, depending on the scan rate), which is characteristic for lithium insertion into anatase lattice, revealing the possible phase transition from titanate to anatase. Obviously, the pair of shoulder redox peaks related to lithium insertion/extraction in anatase becomes larger with increasing milling time, accompanied by a decrease of the broad redox peaks and a structural transformation from titanate to anatase [26].

Figure 6 shows the galvanostatic charge/discharge recyclability for the titanate nanotube and the materials produced by milling treatments. The cutoff potentials for the charge/discharge were set to be $1.0 \mathrm{~V}$ to $3.0 \mathrm{~V}$ versus $\mathrm{Li}^{+} / \mathrm{Li}$. All samples exhibited an obvious drop of discharge capacity during first several cycles that may be due to the formation of $\mathrm{LiO}_{2}$ or $\mathrm{LiOH}$ by left remained water in nanotubes on the surface of electrode [27]. The electrochemical discharge capacities of titanate nanotubes with milling decreased gradually and showed poor cycle stability for lithium insertion and extraction compared to nanotube. In spite of highest value of initial charge and discharge capacities, the short titanate nanotubes produced by milling contain defects in composition and structure, and these defects cause irreversible capacities accumulating every cycles.

\section{Conclusion}

Titanate nanotubes were synthesized by the hydrothermal method and treated in a high-energy ball milling in various duration conditions. The structure of nanotubes was $\mathrm{H}_{2} \mathrm{Ti}_{2} \mathrm{O}_{5} \cdot \mathrm{H}_{2} \mathrm{O}$ with inner and outer diameter of $5 \mathrm{~nm}$ and $10 \mathrm{~nm}$. Increasing milling duration, the titanate nanotubes were fractured into short length of nanotubes, and finally transformed to anatase structure. The $15 \mathrm{~min}$ sample shows that high initial charge and discharge capacities of $280 \mathrm{mAh} \cdot \mathrm{g}^{-1}$ and $336 \mathrm{mAh} \cdot \mathrm{g}^{-1}$ observed in the titanate nanotube, which shows an effect of shorted titanate nanotubes. The length of nanotubes had an effect on cell performance due to high specific surface area for absorption of $\mathrm{Li}$ ion and short nanochannel for easy and fast transfer of $\mathrm{Li}^{+}$for lithium intercalation; however, the cyclic stability was not greatly improved because of structural and compositional defects caused by high-energy ball milling. Further study is required the synthesis of short nanotube without structural 


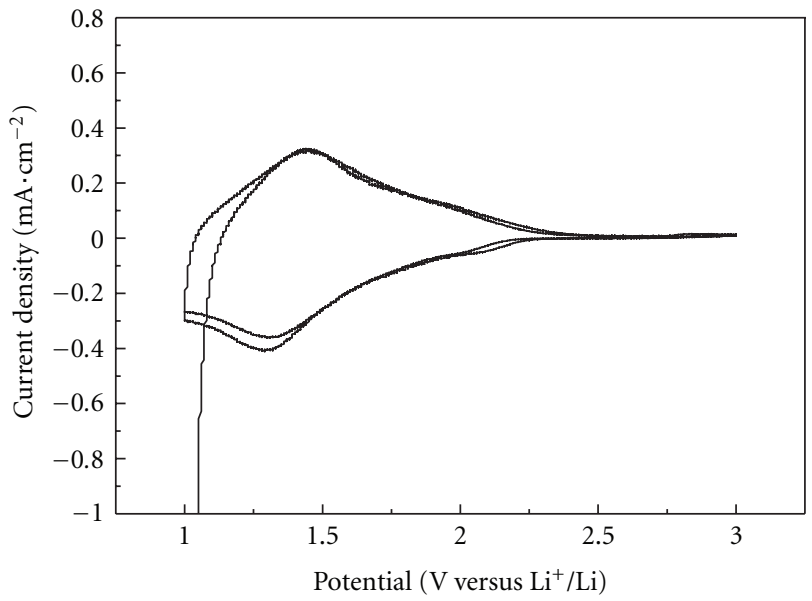

(a)

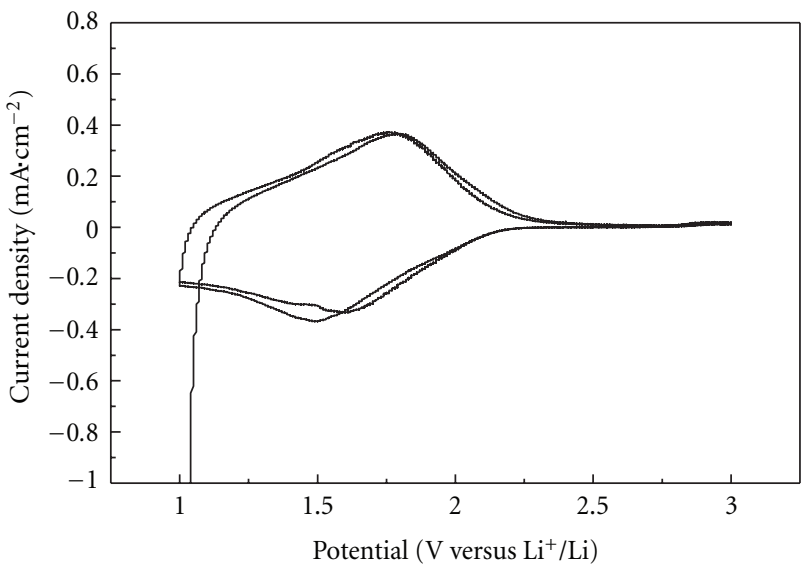

(c)

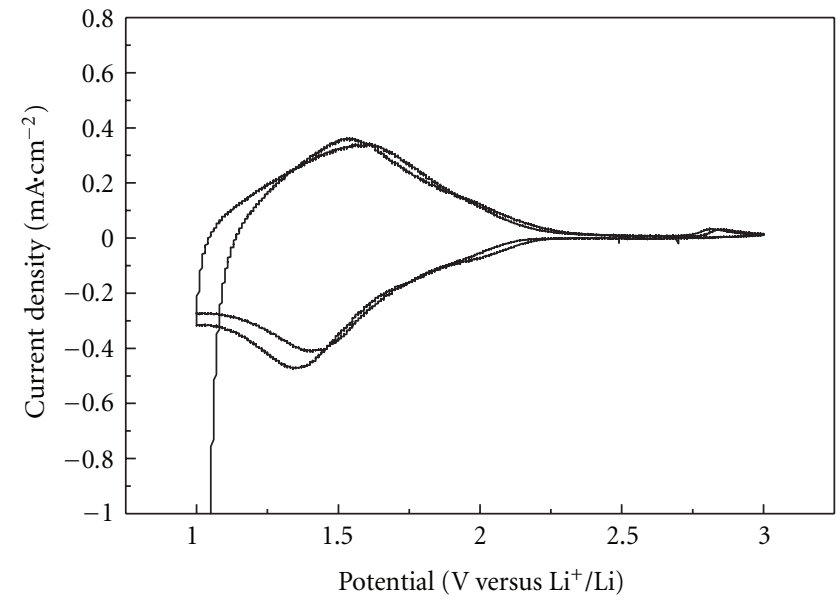

(b)

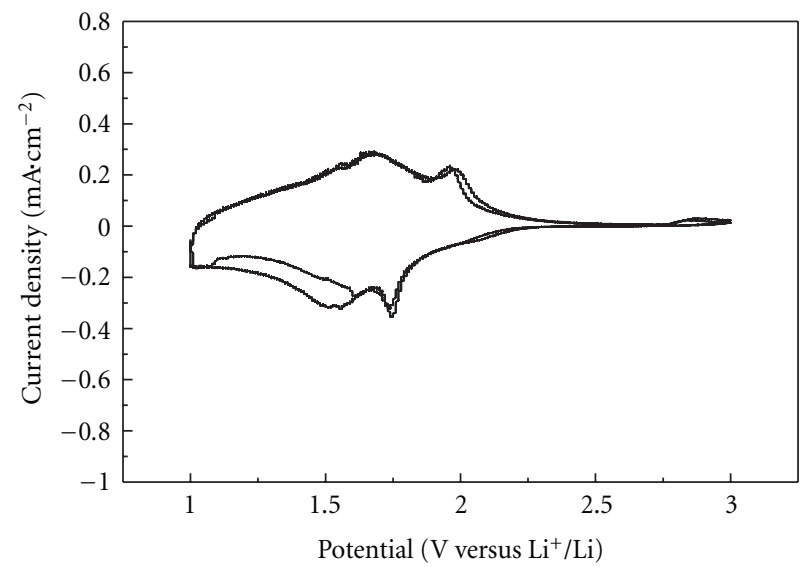

(d)

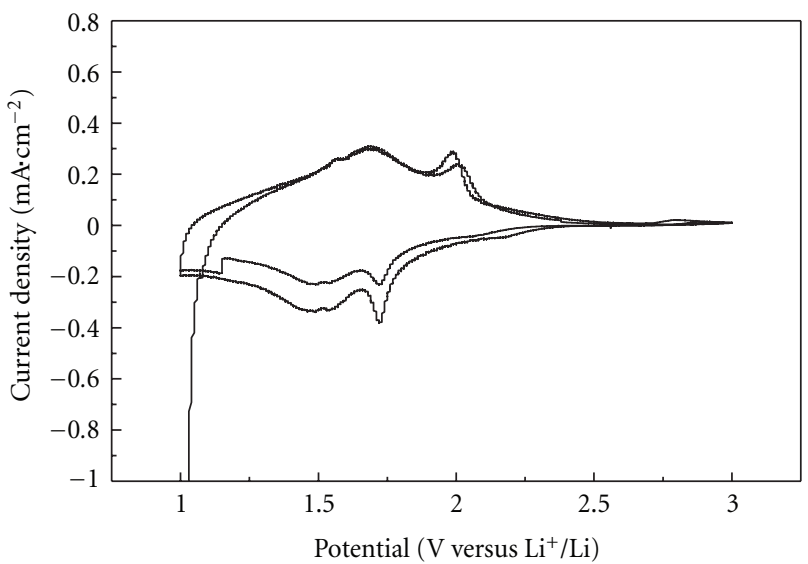

(e)

Figure 5: Cyclic voltammogram plots of $\mathrm{TiO}_{2}$ nanotube electrodes (a) and with mechanical milling in condition of (b) 15, (c) 30, (d) 45, and (e) 60 minutes at $0.2 \mathrm{mV} \cdot \mathrm{s}^{-1}$. 


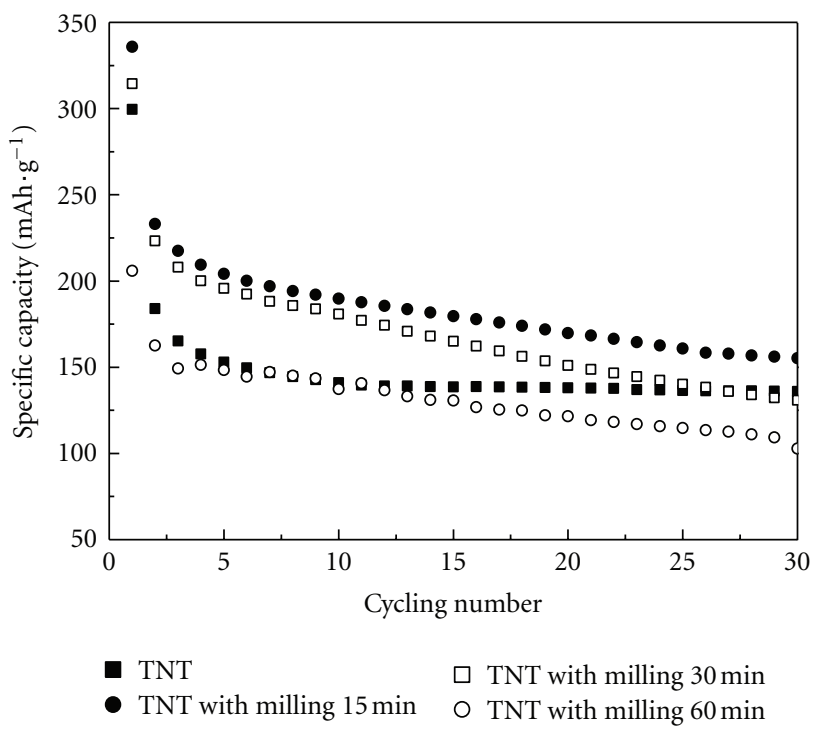

FIGURE 6: Charging-discharging curves of the coin cell composed of titanate nanotubes//1 $\mathrm{M} \mathrm{LiPF}_{6}-\mathrm{EC} / \mathrm{DEC} / / \mathrm{Li}$ metal at a current rate of $10 \mathrm{mAh} \cdot \mathrm{g}^{-1}$ between $1 \mathrm{~V}$ and $3 \mathrm{~V}$. The titanate nanotubes with the millinging condition of $0,15,30$, and 60 minutes were used as an anode-active materials.

change and defect, which can solve the problems of low initial capacity and poor cyclability of titanate nanotubes.

\section{Acknowledgments}

This research was supported by a grant from the Fundamental R\&D Program for Core Technology of Materials funded by the Korean Ministry of Knowledge Economy (Grant no. 10037233).

\section{References}

[1] T. Kasuga, M. Hiramatsu, A. Hoson, T. Sekino, and K. Niihara, "Formation of titanium oxide nanotube," Langmuir, vol. 14, no. 12, pp. 3160-3163, 1998.

[2] D. S. Seo, J. K. Lee, and H. Kim, "Preparation of nanotubeshaped $\mathrm{TiO}_{2}$ powder," Journal of Crystal Growth, vol. 229, no. 1, pp. 428-432, 2001.

[3] Y. Q. Wang, G. Q. Hu, X. F. Duan, H. L. Sun, and Q. K. Xue, "Microstructure and formation mechanism of titanium dioxide nanotubes," Chemical Physics Letters, vol. 365, no. 5-6, pp. 427-431, 2002.

[4] X. Zhang, B. Yao, L. Zhao, C. Liang, L. Zhang, and Y. Mao, "Electrochemical fabrication of single-crystalline anatase $\mathrm{TiO}_{2}$ nanowire arrays," Journal of the Electrochemical Society, vol. 148, no. 7, pp. G398-G400, 2001.

[5] Z. Y. Yuan, J. F. Colomer, and B. L. Su, "Titanium oxide nanoribbons," Chemical Physics Letters, vol. 363, no. 3-4, pp. 362-366, 2002.

[6] J. J. Wu and C. C. Yu, "Aligned $\mathrm{TiO}_{2}$ nanorods and nanowalls," Journal of Physical Chemistry B, vol. 108, no. 11, pp. 33773379, 2004.

[7] X. P. Gao, Y. Lan, H. Y. Zhu et al., "Electrochemical performance of anatase nanotubes converted from protonated titanate hydrate nanotubes," Electrochemical and Solid-State Letters, vol. 8, no. 1, pp. A26-A29, 2005.

[8] J. Li, Z. Tang, and Z. Zhang, "Preparation and novel lithium intercalation properties of titanium oxide nanotubes," Electrochemical and Solid-State Letters, vol. 8, no. 6, pp. A316-A319, 2005.

[9] J. Li, Z. Tang, and Z. Zhang, "H-titanate nanotube: a novel lithium intercalation host with large capacity and high rate capability," Electrochemistry Communications, vol. 7, no. 1, pp. 62-67, 2005.

[10] G. Armstrong, A. R. Armstrong, J. Canales, and P. G. Bruce, "Nanotubes with the $\mathrm{TiO}_{2}-\mathrm{B}$ structure," Chemical Communications, no. 19, pp. 2454-2456, 2005.

[11] G. Armstrong, A. R. Armstrong, J. Canales, and P. G. Bruce, " $\mathrm{TiO}_{2}$ (B) nanotubes as negative electrodes for rechargeable lithium batteries," Electrochemical and Solid-State Letters, vol. 9, no. 3, pp. A139-A143, 2006.

[12] Z. W. Zhao, Z. P. Guo, D. Wexler, Z. F. Ma, X. Wu, and H. K. Liu, "Titania nanotube supported tin anodes for lithium intercalation," Electrochemistry Communications, vol. 9, no. 4, pp. 697-702, 2007.

[13] Y. K. Zhou, L. Cao, F. B. Zhang, B. L. He, and H. L. Li, "Lithium insertion into $\mathrm{TiO}_{2}$ nanotube prepared by the hydrothermal process," Journal of the Electrochemical Society, vol. 150, no. 9, pp. A1246-A1249, 2003.

[14] J. Li, Z. Tang, and Z. Zhang, "Preparation and novel lithium intercalation properties of titanium oxide nanotubes," Electrochemical and Solid-State Letters, vol. 8, no. 6, pp. A316-A319, 2005.

[15] J. Li, Z. Tang, and Z. Zhang, "Controllable formation and electrochemical properties of one-dimensional nanostructured spinel $\mathrm{Li}_{4} \mathrm{Ti}_{5} \mathrm{O}_{12}$," Electrochemistry Communications, vol. 7, no. 9, pp. 894-899, 2005.

[16] J. Li, Z. Tang, and Z. Zhang, "Pseudocapacitive characteristic of lithium ion storage in hydrogen titanate nanotubes," Chemical Physics Letters, vol. 418, no. 4-6, pp. 506-510, 2006.

[17] D. V. Bavykin, V. N. Parmon, A. A. Lapkin, and F. C. Walsh, "The effect of hydrothermal conditions on the mesoporous structure of $\mathrm{TiO}_{2}$ nanotubes," Journal of Materials Chemistry, vol. 14, no. 22, pp. 3370-3377, 2004.

[18] D. H. Kim, J. S. Jang, S. S. Han et al., "High electrochemical Li intercalation in titanate nanotubes," Journal of Physical Chemistry C, vol. 113, no. 31, pp. 14034-14039, 2009.

[19] X. Sun and Y. Li, "Synthesis and characterization of ionexchangeable titanate nanotubes," Chemistry, vol. 9, no. 10, pp. 2229-2238, 2003.

[20] Q. Chen, W. Zhou, G. Du, and L. Peng, “Trititanate nanotubes made via a single alkali treatment," Advanced Materials, vol. 14, no. 17, pp. 1208-1211, 2002.

[21] A. R. Armstrong, G. Armstrong, J. Canales, and P. G. Bruce, " $\mathrm{TiO}_{2}-\mathrm{B}$ nanowires," Angewandte Chemie, vol. 43, no. 17, pp. 2286-2288, 2004.

[22] R. Ma, Y. Bando, and T. Sasaki, "Nanotubes of lepidocrocite titanates," Chemical Physics Letters, vol. 380, no. 5-6, pp. 577582,2003 .

[23] Z. Y. Yuan and B. L. Su, "Titanium oxide nanotubes, nanofibers and nanowires," Colloids and Surfaces A, vol. 241, no. 1-3, pp. 173-183, 2004.

[24] L. Qian, Z. L. Du, S. Y. Yang, and Z. S. Jin, "Raman study of titania nanotube by soft chemical process," Journal of Molecular Structure, vol. 749, no. 1-3, pp. 103-107, 2005. 
[25] M. Plodinec, I. Friščić, D. Iveković et al., "The mechanochemical stability of hydrogen titanate nanostructures," Journal of Alloys and Compounds, vol. 499, no. 1, pp. 113-120, 2010.

[26] L. Kavan, M. Kalbáč, M. Zukalová et al., "Lithium storage in nanostructured $\mathrm{TiO}_{2}$ made by hydrothermal growth," Chemistry of Materials, vol. 16, no. 3, pp. 477-485, 2004.

[27] H. Zhang, G. R. Li, L. P. An, T. Y. Yan, X. P. Gao, and H. Y. $\mathrm{Zhu}$, "Electrochemical lithium storage of titanate and titania nanotubes and nanorods," Journal of Physical Chemistry C, vol. 111, no. 16, pp. 6143-6148, 2007. 

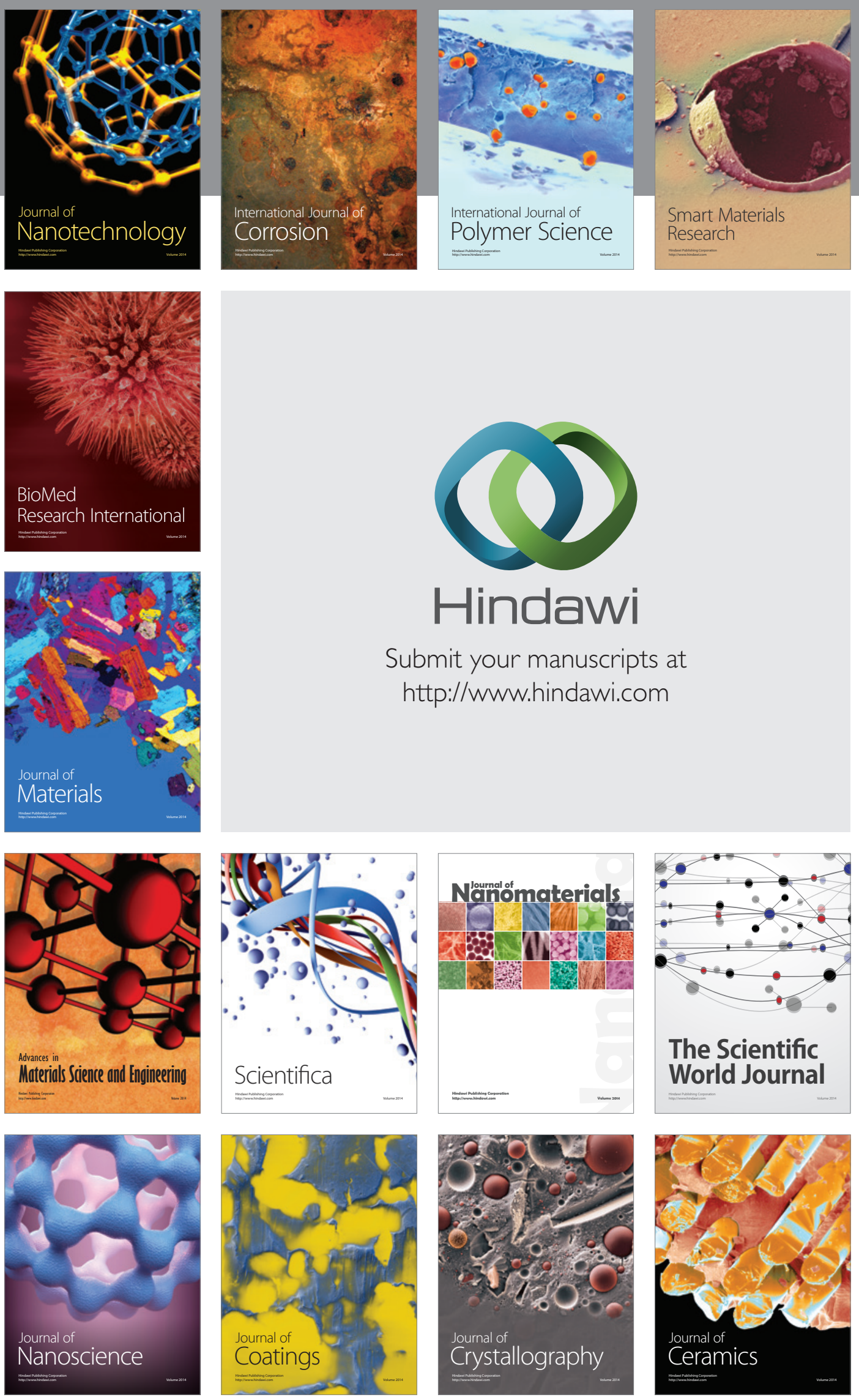

The Scientific World Journal

Submit your manuscripts at

http://www.hindawi.com

\section{World Journal}

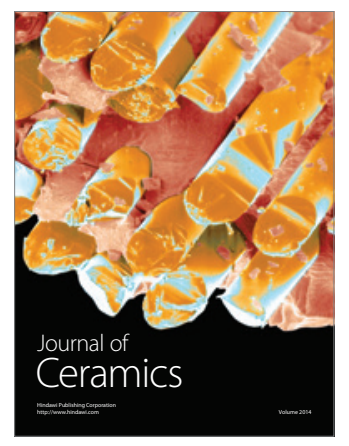

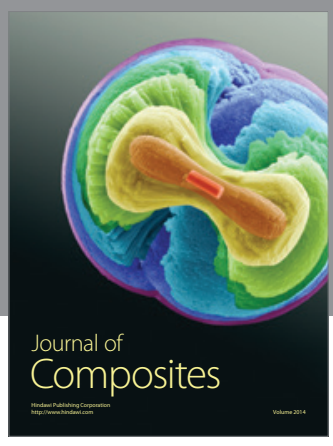
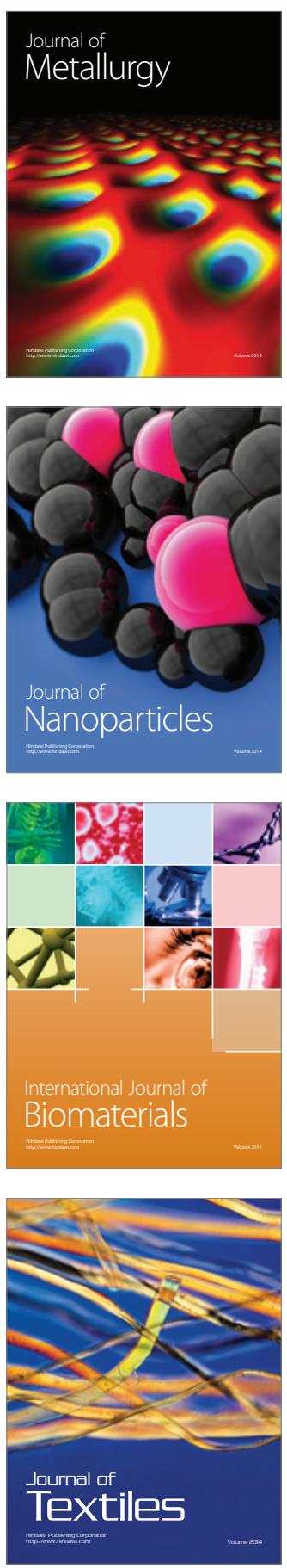